\title{
Acción pública de constitucionalidad. Una mirada a la luz del texto del 2019
}

\author{
Martha Prieto Valdés 1 \\ Amanda Laura Prieto Valdés ${ }^{2}$ de La Habana
}

Revista Derechos en Acción ISSN 2525-1678/ e-ISSN 2525-1686

Año 4/No 12 Invierno 2019 (21 junio a 20 septiembre), 848-863

DOI: https://doi.org/10.24215/25251678e327

\section{Participación popular, necesidad y diversidad de formas}

La concepción de la democracia como forma de gobierno donde el poder está en manos del pueblo, lleva implícita la idea de la PARTICIPACIÓN POPULAR en los asuntos públicos y en el ejercicio del poder político. La más famosa definición de la democracia, dada por Abraham Lincoln en el siglo XIX, como "el gobierno del pueblo, por el pueblo y para el pueblo", muestra la idea del poder popular como elemento esencial de la democracia.

Concebida de diferentes maneras, interesa la concepción como forma de gobierno caracterizada por un conjunto de reglas fundamentales que establecen quién está autorizado para

\footnotetext{
1 Doctora en Ciencia Jurídica y Profesora Titular de Derecho Constitucional y Teoría del Derecho de la Facultad de Derecho de la Universidad de la Habana

2 Máster en Derecho Constitucional y Administrativo y Profesora Asistente de Teoría del Estado, Teoría del Derecho y Derecho Constitucional de la Facultad de Derecho de la Universidad de la Habana.

3 Discurso que pronunció Abraham Lincoln en el siglo XIX, el 19 de noviembre de 1863 en el lugar donde se produjo la batalla de Gettysburg, dentro de la guerra civil de los Estados Unidos, entre los Estados del Norte y los del Sur. Lincoln, A. “El discurso de Gettysburg y otros discursos", El Mundo, Madrid, 2008.
} 
tomar las decisiones colectivas, adoptadas bajo la regla fundamental de la de la mayoría ${ }^{4}$. Lo cierto es que con esta expresión se piensa en aquella sociedad en la que el soberano se involucra por medio de diversos mecanismos de participación directa, como elemento necesario para la funcionalidad democrática, con lo cual le confiere legitimidad no solo a los representantes, sino al diseño. Como modelo político, es esta manera de asumirla la que mejor ha de facilitar a los ciudadanos su capacidad de asociarse y organizarse, de modo que, desde la inclusión y la diversidad, puedan ejercer una influencia directa en las decisiones públicas.

Si todos deben participar en el gobierno de la ciudad, puesto que todos poseen igual competencia política e igual capacidad de juicio para los asuntos políticos, para la toma de decisiones en general, ¿cómo entender la participación? El vocablo participación ha estado sujeto a diversos significados; se habla de participación cuando la gente: asiste a reuniones; cuando sale a la calle a manifestarse a favor o en contra de algo, cuando vota en los procesos electorales, cuando ejecuta determinadas tareas, que pueden ser campañas de alfabetización, de vacunación, u otras; como también cuando hace sentir su voz en una reunión ${ }^{5}$. Todas estas son, sin duda, formas de participación, pero, a nuestro entender, no es limitarse a la opinión y ejecución; la principal forma de participación es la que se realiza a través de la intervención directa en la toma de decisiones, en el control de la ejecución de las medidas adoptadas o políticas formuladas, y en la exigencia de su calidad y efectividad.

Así entonces, aquella participación antes entendida de una manera limitada como actuación a través del representante, no del yo sino por el otro, requiere un cambio hacia un

\footnotetext{
4 Ver Bobiı, N. El futuro de la democracia, Sección de Obras de Política y Derecho, Traducción José F. Fernández Santillán, Fondo de Cultura Económica, México, Primera edición en español, 1986, p. 14.

5 Ver HaRnecker, M. “Nueve Tesis sobre la democracia en los gobiernos de participación popular de América Latina", Revista América Libre № 6, 1994
} 
involucramiento activo, cotidiano y directo en lo político, lo económico y social. Por consiguiente, debe ser entendida la participación como un deber, pero deber moral y no legal; es decir, no ceder titularidad y ejercerla con libertad. En la medida en que el pueblo se implique está incidiendo en el contenido de la toma de decisiones. No participar es una muestra de libertad individual, pero la no participación puede provocar lesión del interés social que se quiera alcanzar o proteger.

Es cierto que el cómo participar también es plural, pero si un medio de participación ha de preservarse y reclamarse, como expresión de esa conjunción entre la titularidad soberana y el ejercicio del poder, junto a la necesidad de verificación de la labor de los representantes, de la comprobación, inspección, fiscalización, del cumplimiento de lo acordado, de lo estipulado jurídicamente, es el control.

Aunque pudiera parecer elemental, vale significar que no huelga decir que el control no es sinónimo de restricciones, aunque se le conciba como medio de contrarrestar el exceso de poder, arbitrariedades y vulneraciones de derechos. Por ello mismo, debe ser entendido -en cuanto a su eficacia-, como un medio de garantía o de defensa de derechos frente a abusos de poder, a corrupción, a desconocimiento de valores y principios constitucionales. La supervisión, verificación o comprobación que tal acción significa, en cualquier diseño político, es necesaria para verificar el cumplimiento de lo establecido, a la vez que propicia el mantenimiento del equilibrio en el aparato de poder, como también corregir o rectificar desviaciones en las diversas esferas. También es vital frente a factores de desestabilización de la actividad de la Administración Pública en los diferentes niveles de organización.

No es restricción de los espacios competenciales o atribuciones; pero sí forma una triada necesaria con responsabilidad y seguridad, y en tales sentidos debe instrumentarse en todo momento para asegurar el desarrollo de la libertad en sociedad. Este control también puede y debe ser estimulado por el pueblo: 
el ejercicio de la ACCIÓN DIRECTA PÚBLICA de los destinatarios en esta actividad es una de las vías más necesarias para permitir la conjugación entre participación y representación.

No bastan ya los principios clásicos de la democracia representativa: división de poderes del Estado, alternancia en el poder de las autoridades, consultas periódicas a la ciudadanía en procesos electorales, radicación de la soberanía en el pueblo, etc.

\section{Cuba, situación actual a la luz del proyecto de texto constitucional, 2019}

La relación individuo-sociedad-Estado sugiere una estrecha interconexión entre todos los actores sociales, y así tiene que ser si se pretende armonía social, no sin contradicciones y diferencias, pero necesarias en pos del desarrollo de la sociedad. Pero también tiene que haber un respeto a lo individual, a los intereses particulares de cada persona, del colectivo o región, los que deberán poder realizarse sin necesidad de afectar lo general o común.

En Cuba, al amparo del texto del $2019^{6}$ se tienen varios mecanismos de participación popular. Además del ejercicio del voto en elecciones y referendo, está prevista la participación en rendiciones de cuentas de los delegados como medio de control y antecedente de una futura revocación del mandato popular, acompañado de una iniciativa legislativa de muy difícil promoción ciudadana (10 mil ciudadanos $)^{7}$.

Siguiendo con la mirada en Cuba, es imposible desconocer que el diseño general en cuanto a la participación ciudadana es

6 Este artículo se ha escrito luego del voto aprobatorio en referendo popular del 24 de febrero de 2019 y antes de que se proclame y entre en vigo el tecxto constitucional de 2019. Por esto, en el presente articulo se utilizarán las expresiones proyecto y texto.

7 Mecanismo de participación popular que se preserva de la Constitución de la República de Cuba de 1976, Ref., art.88, inc. g). Para su formulación actual ver Proyecto de Constitución de la República de Cuba de 2019, art.164, inc. k) 
válido y ha sufrido modificaciones, aun cuando toca no cerrar las puertas ante las limitaciones que han existido y pueden existir en su instrumentación cotidiana y su tutela como principios ${ }^{8}$. Uno de estos últimos es la reformulación para su disfrute en el ámbito municipal ${ }^{9}$, como también la iniciativa ciudadana para estimular la reforma de la Constitución ${ }^{10}$, respecto a la cual sería prudente se flexibilizara la concepción de los requisitos para la promoción que hoy existen ${ }^{11}$, de lo contrario será de muy difícil ejercicio.

Entonces, no basta regulación, o diseñar e introducir nuevas fórmulas, se requiere de una cultura y conciencia participativa que aseguren una real y efectiva democracia. Pero ¿en qué espacios ha de preverse la participación?, el reclamo es para que se produzca a todos los niveles, aunque el más viable es a nivel local, en los municipios.

8 Ver Proyecto de Constitución de la República de Cuba de 2019, art. 101: Los órganos del Estado se integran y desarrollan su actividad sobre la base de los principios de la democracia socialista que se expresan en las reglas siguientes: a) todos los órganos representativos de poder del Estado son electivos y renovables; b) el pueblo controla la actividad de los órganos estatales, de sus directivos y funcionarios, de los diputados y de los delegados, de conformidad con lo previsto en la ley; c) los elegidos tienen el deber de rendir cuenta de su actuación periódicamente y pueden ser revocados de sus cargos en cualquier momento; ... h) los órganos del Estado, sus directivos y funcionarios actúan con la debida transparencia.

9 Ver Proyecto de Constitución de 2019, Garantías a los derechos de petición y participación popular local, art. 185 y ss.

10 Ver Proyecto de Constitución de 2019, art. 227. Tienen iniciativa para promover reformas a la Constitución: f) los ciudadanos, mediante petición dirigida a la Asamblea Nacional del Poder Popular, suscrita ante el Consejo Electoral Nacional, como mínimo por cincuenta mil electores. La ley establece el procedimiento, los requisitos y garantías para su solicitud y realización.

11 Aunque la regulación de la intervención ciudadana es solo para Ley ordinaria, los requisitos previstos en el Reglamento pueden ser restrictivos para su ejercicio. Ver Reglamento de la Asamblea Nacional del Poder Popular de 1996, art. 64 (Todo ello, amén de la necesaria actualización normativa que se realizará). Si la iniciativa procede de los ciudadanos, conforme se establece en el inciso k) del artículo 164 del Proyecto de Constitución, además de la fundamentación consignada en los acápites precedentes, los ciudadanos promoventes del proyecto, acompañan declaración jurada ante notario, donde se acreditará la identidad personal mediante los datos del carné de identidad como documento idóneo y probatorio de la individualización de una persona, así como de que no está invalidada para ejercer el sufragio activo 0 pasivo. 
En este sentido, pensando en los municipios cubanos, deben explotarse las potencialidades municipales para conformar una hacienda sólida, que le permitan afrontar y solucionar los reclamos y mandatos de los residentes en el municipio, (TODOS, sin diferenciar ciudadanía), lo cual propiciará, además del desarrollo conforme a las características propias de cada localidad, la credibilidad en las instituciones locales. Solo así, autoridad real y titularidad formal irán de la mano; y el Poder Popular gozará de legitimidad pues el pueblo apreciará acciones directas de sus instituciones locales con capacidad de gestión para la atención de las demandas básicas ${ }^{12}$.

Entonces, desde una perspectiva fáctica o sociológica de su existencia como parte del aparato estatal, no caben dudas de que su finalidad se halla vinculada con el servicio y la satisfacción de las exigencias mínimas de los integrantes del territorio que debe tener competencia y capacidad para poder cumplir con ellas. Si la letra constitucional de 1976 los calificó de sociedad local, con personalidad jurídica a todos los efectos legales, organizada políticamente por la ley, en una extensión territorial determinada por necesarias relaciones económicas y sociales de su población, con capacidad de satisfacer las necesidades mínimas locales ${ }^{13}$; ¿por qué no fraguó así? He aquí una disfuncionalidad constitucional, ya que la letra mayor no se entendió como elemento de compulsión y límite jurídico político, y los municipios no pasaron de ser espacios locales sujetos a la determinación provincial y nacional.

Esta necesidad de cambio se aprecia en el Proyecto constitucional, toda vez que se concibe al municipio como "la sociedad

\footnotetext{
12 Prieto Valdés, M. “¿Qué municipios necesitamos? Algunos principios para su configuración", Pérez Hernández, L. y Díaz Legón, 0. (Coords.). ¿Qué municipio queremos? Respuestas para Cuba en clave de descentralización y desarrollo local, Editorial UH, La Habana, Cuba, 2015, pp. 155 a 173.

13 Constitución de la República de Cuba 1976, Ref. 1992, art. 102: ... El municipio es la sociedad local, con personalidad jurídica a todos los efectos legales, organizada políticamente por la ley, en una extensión territorial determinada por necesarias relaciones económicas y sociales de su población y con capacidad para satisfacer las necesidades mínimas locales....
} 
local, organizada por la ley, que constituye la unidad políticaadministrativa primaria y fundamental de la organización nacional; goza de autonomía y personalidad jurídica, (...) con el propósito de lograr la satisfacción de las necesidades locales ${ }^{14}$ ". Es en este sentido que la autonomía del municipio comprende, además de la elección de sus autoridades, la facultad para decidir sobre la utilización de sus recursos y el ejercicio de las competencias que le corresponden, con arreglo a la Constitución y a las leyes.

Todos estos cambios han de contribuir a una modificación en la concepción de qué y cómo hacer y de quiénes están llamados a intervenir. Cuba, aun cuando posee un diseño político peculiar, resultado de las conjunciones de diversas influencias: la colonial hispánica, la norteamericana y la soviética, todo ello cocinado en un caldo de criollez, tiene rasgos e instituciones valiosos, como también otros que merecen atención, por lo que el perfeccionamiento de la interacción de las categorías de ciudadanía, democracia, representación, participación y acción directa es una necesidad.

Entonces, restan unas pocas propuestas. Si el Siglo XX tuvo a la Democracia como una de las ideas centrales, este Siglo XXI

\footnotetext{
14 Proyecto de Constitución de la República de Cuba de 2019, art.168. El municipio es la sociedad local, organizada por la ley, que constituye la unidad política-administrativa primaria y fundamental de la organización nacional; goza de autonomía y personalidad jurídica propias a todos los efectos legales, con una extensión territorial determinada por necesarias relaciones de vecindad, económicas y sociales de su población e intereses de la nación, con el propósito de lograr la satisfacción de las necesidades locales. Cuenta con ingresos propios y las asignaciones que recibe del Gobierno de la República, en función del desarrollo económico y social de su territorio y otros fines del Estado, bajo la dirección de la Asamblea Municipal del Poder Popular; art.169. La autonomía del municipio comprende la elección 0 designación de sus autoridades, la facultad para decidir sobre la utilización de sus recursos y el ejercicio de las competencias que le corresponden, así como dictar acuerdos y disposiciones normativas necesarias para el ejercicio de sus facultades, según lo dispuesto en la Constitución y las leyes.

La autonomía se ejerce de conformidad con los principios de solidaridad, coordinación y colaboración con el resto de los territorios del país, y sin detrimento de los intereses superiores de la nación.
} 
tiene que seguir siendo el que permita los pasos certeros que aseguren su efectiva realización. Cuba también está insertada en esta dinámica y debe actuar en pos de sobrepasar el espacio de lo creado para llegar al espacio de lo querido posible, ha de superar la cultura de la declaración por la cultura de la acción.

\section{Acción pública como mecanismo de participación popular}

Contestes estamos en que no ha habido a través de la historia una postura armónica acerca de lo que es la acción, y ello ha influido en las normativas que se han adoptado y viceversa; ampliando o limitando su contenido, ofreciendo menores o mayores posibilidades para recabar en juicio protección o solución de las pretensiones. Es por ello, útil un breve comentario acerca de la evolución histórica de la concepción de la acción y su naturaleza jurídica, por ser ella el presupuesto de entrada al proceso y al control de constitucionalidad ${ }^{15}$.

Si bien el inicio de las acciones se remonta a los tiempos de Roma, concebida primeramente como la posibilidad genérica de actuar en defensa de un derecho y perseguir en juicio su reconocimiento, se fue moviendo hacia la noción de derecho ${ }^{16}$, postura última sostenida durante el medioevo y más tarde por SAVIGNY, al significar que ella era la trasformación del derecho subjetivo material, para la defensa de este, frente a su vulneración ${ }^{17}$. De actuación prevista por la ley para instar a juicio en reclamo de pretensión o presunto derecho, se transformó en parte de ellos; en expresión condensada del derecho subjetivo,

\footnotetext{
15 Ver GozAínı, A, Introducción al Derecho Procesal constitucional, Rubinzal-Culzoni eds., Buenos Aires, s.f., p. 16.

16 Para abundar, consúltense las acciones de la Ley, las formulas y excepciones del proceso civil romano que sentaron las bases para la noción primaria y más tarde las modificaciones introducidas por Justiniano cuando la definió como "Actio nihil aliud est quam ius persequendi in iudicio quod sibi debetur" (Instituciones de Justiniano, IV, 6, De actionibus, proemio) 17 Ver Savigny, F, Sistema de Derecho romano actual, Tomo IV s.e., México, SCT, 2004, p. 8,
} 
que ya a esta altura tenía como fines la defensa de derechos civiles personales y también patrimoniales.

En este camino hacia el presente, los franceses defendieron la existencia de una actio de carácter general, diferenciada del derecho que se defendía, aunque ligado a él ${ }^{18}$, pero el toque fuerte para la construcción cuasi final lo aportaron las posturas alemanas. Estos últimos, con dualidad de expresiones ${ }^{19}$, la entendieron tanto como derecho a querellarse contra el obligado como frente al Estado a fin de propiciar la tutela jurídica ${ }^{20}$ a partir de la estimulación del aparato de justicia para que interviniese y decidiese. La acción devenía en un derecho subjetivo público, autónomo, de carácter abstracto y diferente del derecho subjetivo sustantivo, como derecho de todo gobernado a solicitar del Estado la prestación jurisdiccional ${ }^{21}$.

No puede tampoco desconocerse la posición asumida por Chiovenda, que dio un giro a la postura alemana, y se desvió un tanto de la noción de la acción como expresión de un derecho subjetivo para reaccionar contra su violación; y la cataloga como un derecho autónomo, pero de carácter potestativo y, a través del cual se ejerce el poder de influir y producir un efecto

18 Al decir de Halpérin, "El esquema del Código Civil es el reflejo de la reinterpretación de la división tripartita (personas-bienes-acciones) de las Institutes de Justiniano por los teóricos del derecho natural, en función de sus ideas individualistas y racionalistas", en Le Code Civil (trad. Muñoz Pizarro); Santiago de Chile, 2008; p. 89, disponible en http://www.tesis.uchile.cl/ tesis/uchile/2008/de-munoz_m/pdfAmont/de-munoz_m.pdf, consultado el 25 de marzo de 2015 , a las $14: 23$ horas.

19 Klage, (demanda o queja, empleada como derecho a obtener la protección judicial de un interés) y Ansprucht exigencia o pretensión que en sede civil se expresaba en "el derecho a exigir de otro una acción u omisión")

20 Ver Goldschmidt, J., Derecho Procesal Civil, (trad. De Leonardo Prieto Castro), Ed. Labor, S.A., Madrid, 1936, p. 96 y ss.

21 Ver Fix-Zamudio, H., Introducción al Derecho Procesal constitucional, p. 51, disponible en http://s3.amazonaws.com/academia.edu.documents/37129335/03_-_Hector_FixZamudio_Introduccion_al_derecho_procesal_constitucional.pdf?AWSAccessKeyld=AKIAJ56T QJRTWSMTNPEA\&Expires=1479088634\&Signature=ZCLKWG6c2dhXcUaRhw0zosYOV2I\% 3D\&response-content-disposition=inline\%3B\%20filename\%3DINTRODUCCION_AL_DERECHO_PROCESAL_CONSTIT.pdf, consultado el 25 de marzo de 2015 a las 12:23 horas. 
jurídico en favor de un sujeto mediante un proceso, como poder de realización de la voluntad concreta de ley, que prescinde de la voluntad y de la prestación del demandado ${ }^{22}$.

Hasta esa primera mitad del siglo XX, como bien afirmara CALAMANDRE se han manifestado a través de la historia dos grandes corrientes respecto a la naturaleza jurídica de la acción: una es abstracta, para surtir efectos generales, a partir de la función útil del Derecho en la sociedad; y la otra concreta para efectos específicos, como un poder puesto en garantía de una cierta situación de derecho sustancial a ser reconocido por el ente judicial ${ }^{23}$. Más recientemente se han desarrollado otras ${ }^{24}$ que la vinculan al acceso a la justicia, al derecho de acceso e incluso a la tutela judicial; no por gusto el propio Calamandrei dijera que "la historia y la crítica de las teorías sobre la acción..., como las noches de la leyenda, son mil y una, y todas maravillosas" 25 .

No obstante tales diversas posturas ${ }^{26}$, esa acción, ya sea parte o expresión propia del derecho subjetivo que se reclama; sea una derivación del derecho sustancial; un derecho de ejercicio individual o colectivo para la defensa de otros derechos o intereses de diversa índole; o sea una institución procesal autónoma y potestativa, debe estar concebida para actuar tanto en reclamos genéricos o específicos, entendiéndola como

\footnotetext{
22 Ver Chiovenda, G., Curso de Derecho Procesal Civil (trad. De Sentís Melendo) Ed. Ejea, Buenos Aires, 1949, pp. 10-13.

23 Ver Calamandrei, P. , (trad. de Sentís Melendo), Los Estudios de Derecho procesal en Italia, Ediciones jurídicas Europa-América; Buenos Aires, 1959, pp. 137-138.

24 Ver Chiovenda, G., La acción en el sistema de los derechos, Ed. Temis, Bogotá, 1949. Goldschmidt, J., Derecho Procesal Civil, (trad. de Prieto, L.) Ed. Labor, Barcelona, 1936.

25 Ídem., p. 140

26 Para ampliar acerca de la diversidad actual de posturas, consúltese Brodermann Ferrer.

L., "Tesis Ecléctica sobre las teorías modernas de la acción (armonía entre concretas y abstractas)" en Ferrer Mac-Gregor, E. y Zaldívar Lelo de Larrea, A. (coords.) La Ciencia del Derecho Procesal Constitucional. Estudios en homenaje a Héctor Fix-Zamudio en sus 50 años como investigador del Derecho. T.X., Tutela Judicial y Derecho Procesal, Ed. UNAM, México D.F., 2008, pp. 181-207.
} 
"derecho-medio, como el cordón umbilical a través del cual el derecho sustancial circula en el proceso y lo alimenta..." Desde esta visión, se instituye en la polea que estimula a la función judicial a fin de que intervenga en la valoración y solución de reclamos de entes privados.

Pero aquí no puede quedar la formulación si se quiere que sea garantista; no puede entenderse como instituto separado correspondiente a cada rama del Derecho ${ }^{28}$, ni con significado diferente en cada campo. Como sostuviera Couture y con visión unificadora, debe ser entendida como poder jurídico de acudir ante los órganos jurisdiccionales, con o sin derecho, con pretensión concreta o sin ella; pues "[E]l poder de accionar es un poder jurídico de todo individuo en cuanto tal; existe aun cuando no se ejerza efectivamente" ${ }^{29}$, ya sea en reclamo frente a entes particulares o de protección estatal, pero en todo caso se procura la intervención del aparato de justicia, con lo que se le otorga un carácter público a la misma ${ }^{30}$.

Por consiguiente, poder ejercer la acción frente al ente judicial es el primer presupuesto jurídico garantista que se necesita para la realización de los derechos y del Derecho; así como para promover el control político sobre la constitucionalidad y legalidad de las disposiciones normativas y decisiones de todos los órganos estatales, ya sea por interés general o particular.

¿Cómo estimular un control que ha sido insuficiente? Se requiere de la participación popular no solo que ejecute, sino que promueva y controle.

\footnotetext{
27 Calamandrei, P. , op. cit., p. 145

28 Ver Carneluttı, F. (trad. de Sentís Melendo), Lezioni sul proceso penale, Ed. Ejea, Buenos Aires, 1950. Se pronunció en defensa de la unidad de acción civil y penal.

29 Couture, E., Fundamentos del Derecho Procesal Civil, $3^{\text {a }}$ edición (póstuma), Roque Depalma Ed, Buenos Aires, 1958, p, 68

30 Ídem, p. 69 y ss.
} 


\section{El control de constitucionalidad posterior como medio para asegurar la eficacia constitucional, y para Cuba para relegitimar la participación popular que aprobó la Constitución}

La realización de la Constitución clama por un control, previo o posterior que lo prevea y asegure. En tanto texto de superior fuerza y rango jurídico, pensando en presente y un futuro inmediato, debe con inmediatez reformularse el diseño de control político de constitucionalidad, dando entrada al aparato de justicia y a la intervención popular directa, individual y colectiva, en su estimulación y exigencia. Más de 40 años de experiencia de un control político concentrado previo y posterior no ha dado los frutos satisfactorios que se esperaban en la conjugación del bienestar local y el nacional; individual y colectivo.

Pero, sin una cultura y conciencia jurídica de toda la sociedad, dirigentes y destinatarios de las normas, de respeto a la letra superior y del derecho-deber de todos en pos de ello, los contenidos del texto constitucional nunca serán realidad.

El control jurídico de constitucionalidad es una urgencia, por eso, de no admitirse la nueva estructura, deben los tribunales ordinarios realizar un control difuso con la finalidad de asegurar la jerarquización de las disposiciones frente a normativas o decisiones inferiores restrictivas. Si el tribunal actuante advierte que la disposición inferior vulneradora es evidentemente inconstitucional, que debió ser nula $a b$ initio por restringir el alcance o contradecir a la normativa de mayor rango, resolverá el caso inaplicando el precepto infraconstitucional y restituirá/reconocerá el derecho de conformidad con la ley superior. Sencillamente, resolverá la antinomia. Si la advertencia proviene de la parte afectada y el tribunal de base tiene alguna duda al respecto, pudiera cursar consulta -por vía incidental- al Consejo de Gobierno del Tribunal Supremo Popular para que emita criterios acerca de la constitucionalidad, en cuanto al caso que se evalúa, de la normativa presuntamente vulneradora, sin 
tener que esperar por solicitud de la Asamblea Nacional del Poder Popular o del Consejo de Estado para pronunciarse al respecto, como sí sucede hoy ${ }^{31}$.

Para el control concreto, los tribunales ordinarios si pueden y deben brindar solución a las reclamaciones por vulneración de los derechos regulados constitucionalmente y de la normativa superior ${ }^{32}$, pues el hecho de que estos órganos declaren “...que un acto cualquiera, legislativo o administrativo, sea nulo por oponerse a la Constitución... no implica un veto a otro [órgano o sus facultades], sino la determinación de la norma aplicable al caso concreto, lo cual significa esencialmente administrar justicia".

Por consiguiente, la intervención judicial, ya concentrada o difusa es siempre posible y válida, pues “... al fallar un caso concreto están en el deber de buscar la norma aplicable, y cuando desechan una para escoger otra, no están derogando ni vetando la norma desechada, sino limitándose a declarar cual es el (D)erecho en el caso concreto sometido a su decisión" ${ }^{33}$, y con ello no se invade el espacio competencial de los órganos representativos, o de otros entes estatales.

En pos de estimular el control general y abstracto ante la Asamblea Nacional del Poder Popular que se preserva en el Proyecto, sería muy prudente retomar las acciones individuales y colectivas ante la propia Asamblea como estaba establecido en el Reglamento de $1982^{34}$, a los efectos de verificar la corres-

\footnotetext{
31 Ver Ley No.82 de los Tribunales Populares

32 Expresión de esta última forma de intervención del Tribunal supremo, sin la necesidad de creación de sala especial, se tiene en la Constitución de 1901; ver art. 83: Además de las atribuciones que le estuvieren anteriormente señaladas y de las que en lo sucesivo le confieran las leyes, corresponden al Tribunal Supremo las siguientes: 4.Decidir sobre la constitucionalidad de las leyes, decretos y reglamentos, cuando fuere objeto de controversia entre partes.

33 Álvarez Tabío, F.: El Recurso de inconstitucionalidad, ob. cit., pp. 8-9.

34 Ver Reglamento de la Asamblea Nacional del Poder Popular de 1982, Disposición Transitoria Única, a).
} 
pondencia de las normativas locales frente a las superiores, derogándose las restrictivas de las reglas, principios y valores superiores y aquellas que afectan derechos constitucionales y ordinarios.

Para asegurar la supremacía jurídica del magno texto, pudiera acogerse una de las siguientes propuestas:

VARIANTE 1: Resultante de la defensa directa del derecho constitucional en sede ordinaria, se instrumenta el control judicial de la constitucionalidad, indirecto, incidental y respecto al caso, por lo que la decisión judicial no expulsa la normativa del ordenamiento jurídico.

El control de constitucionalidad se efectuaría respecto de las leyes y decretos leyes, y el de legalidad respecto a las disposiciones del gobierno, la administración, o asambleas locales del poder popular, a instancias de parte en defensa de los derechos. Se dará cumplimiento al precepto constitucional consagrado en el artículo 26, no realizado hasta el presente, más bien limitado por Ley de Procedimiento Civil, Administrativo, Laboral y Económico de 1977, por el art. 657, epig. 4 y 6, ya comentado.

VARIANTE 2: Establecer el control de constitucionalidad directo, expreso y concentrado en sede judicial, mediante proceso especial y ante sala especial del Tribunal Supremo Popular, cuya decisión de solución a las contradicciones normativas y se produzca la determinación de la validez formal y material de las disposiciones cuestionadas. Incorporar activamente a la ciudadanía, en la promoción de la revocación de disposiciones restrictivas de derechos consagrados constitucionalmente, mediante el reconocimiento del pleno acceso a la justicia, ya individual o colectivo.

VARIANTE 3: Establecer el control mixto de constitucionalidad que estimule garantía de derechos y del orden en Sala especial del Tribunal Supremo Popular. No ha de menoscabarse la posibilidad de conformación de la Sala especial para lo Constitucional o Sala de Garantías dentro del Tribunal Supremo 
Popular para contribuir a la armonía normativa a través de precisos juicios de validez y un cauce hacia la seguridad jurídica como antesala de la Justicia; asegurar la relegitimación del texto superior en su lugar y grado, y para que sea voz última en las reclamaciones de derechos constitucionales, o garantía específica necesaria a los derechos esenciales para el hombre.

De las variantes propuestas, la primera puede ser efectiva sin modificación normativa alguna; solo la segunda recaba de reforma constitucional al extraer de la Asamblea Nacional tal atribución y consagrarla en exclusivo en la Sala especial; mientras que la tercera solo requiere de adecuación de las disposiciones ordinarias.

Así entonces, de conformidad con la letra constitucional vigente, para lograr el aseguramiento de la inalterabilidad de sus contenidos de inmediato, es una exigencia abordar lo constitucional, diferenciado de lo legal u ordinario, distinguir los órganos intervinientes y sus facultades, los efectos de las decisiones, junto a la identificación de los entes responsables en cada caso. Ello hará más factible la instrumentación del control posterior de constitucionalidad concentrado en la Asamblea Nacional del Poder Popular, y el de legalidad que ejercen los demás órganos como parte de la verificación del funcionamiento de los inferiores en los marcos legales previstos.

\section{Ideas finales}

Teniendo a la Constitución como conjunto normativo de mayor jerarquía del ordenamiento jurídico de la sociedad, aún con la ausencia de tutela expresa del pleno acceso o el derecho de acceso a la justicia, puede y debe asegurarse su realización. Aún sin regulación precisa y formal en las leyes procesales o la ley de los Tribunales, puede y debe hacerse. Es momento de que se abandone la interpretación declarativa, que explica precepto a precepto y se tenga al texto normativo, tanto la Constitución, como el resto de las normativas, como un todo. 
En otras palabras, todos los tribunales pueden y deben resolver las antinomias respecto a la Constitución en cuanto reclamación conozcan, adoptando la decisión para el caso concreto, mediante la inaplicación de la inferior restrictiva o contradictoria. Y, en tanto no se cree procedimiento especial, ante Sala especial, le correspondería al Tribunal Supremo emitir el dictamen de constitucionalidad y los argumentos para la derogación de la normativa, quedando a decisión de la Asamblea Nacional del Poder Popular, la declaración de inconstitucionalidad con efectos generales, como expresión del control político establecido en el art. 108 incisos e) del Proeyecto de Constitución de la República de Cuba de 2019.

Lo anterior no niega que se sigan perfeccionando las dinámicas de otros órganos e instituciones político administrativas que participan tanto en la defensa de los derechos como en el control, ni de la viabilidad de considerar al ciudadano -individual y colectivamente- como parte principal y estimulador del proceso de control político de la constitucionalidad ante la Asamblea Nacional respecto a las Leyes, Decretos Leyes y Decretos, con efectos erga omnes, hasta tanto no se modifique el diseño de control político imperante.

Estas propuestas contribuirán, desde una actuación consciente y activa de todos, a evitar una desconstitucionalización del orden normativo, y un cauce hacia la inseguridad jurídica ${ }^{35}$, a la vez que una deslegitimación del sistema político imperante.

Si se desea asegurar la eficacia del espíritu y la letra constitucional como garantía superior de los derechos y el orden consagrado, ha de darse el paso para el reconocimiento e instrumentación de los medios necesarios para su preservación, defensa y disfrute, con formas viables que permitan que el hombre pueda realizar en la sociedad su plena dignidad.

35 Ver Prieto Valdés, M., "La Constitución y el Poder, y el poder de la Constitución”, en Visión iberoamericana del tema constitucional. Fundación M. García-Pelayo, Caracas, 2003, pp. 232-233. 